\title{
INVISÍVEIS SOCIAIS: A NEGAÇÃO DO DIREITO À CIDADE À POPULAÇÃO EM SITUAÇÃO DE RUA
}

\author{
INVISIBLES SOCIAL: THE DENIAL OF RIGHT TO THE CITY TO THE \\ POPULATION IN STREET SITUATION
}

\author{
${ }^{1}$ Domingos do Nascimento Nonato \\ ${ }^{2}$ Raimundo Wilson Gama Raiol
}

\section{RESUMO}

Analisa-se o processo deliberado e sistemático que invisibilisa as pessoas em situação de rua no Brasil, discutindo o quanto isso é pernicioso à luz dos direitos humanos, porque lhes subtrai o gozo do direito à cidade. Optou-se metodologicamente pela pesquisa bibliográfica e documental. Tratar da intrínseca relação entre população em situação de rua e o direito à cidade justifica-se porque é uma questão que carece de justo e adequado enfretamento político por parte do Poder Público, frente às inúmeras práticas de violências institucionalizadas ou não que tais pessoas sofrem, combinado com o elevado grau de miserabilidade que vivenciam.

Palavras-chave: População em Situação de Rua. Direito à Cidade. Estigma. Grupo Vulnerável. Invisíveis Sociais.

\begin{abstract}
Analyzes the deliberate and systematic process that invisibilisa people on the streets in Brazil, discussing how it is pernicious in light of human rights, because it subtracts them the enjoyment of the right to the city. We chose methodologically the bibliographical and documentary research. This the intrinsic relationship between street population and the right to the city situation is justified because it is an issue that lacks fair and appropriate political coping by the Government, facing the numerous practices of institutionalized violence or not such persons suffer, combined with the high degree of misery they experience.
\end{abstract}

Keywords: Population in Street Situations. Right to the City. Stigma. Social Exclusion. Social Invisibles.

\footnotetext{
${ }^{1}$ Doutorando em Direitos Humanos pela Universidade Federal do Pará - UFPA, Pará (Brasil).

E-mail: dnnonato@yahoo.com.br

${ }^{2}$ Doutor em Direitos Fundamentais e Relações Sociais pela Universidade Federal do Pará - UFPA, Pará (Brasil). Professor da Graduação e Pós-Graduação em Direito pela Universidade Federal do Pará - UFPA, Pará (Brasil). E-mail: rwraiol@gmail.com
} 


\section{NOTAS INTRODUTÓRIAS}

Não é de difícil constatação que as pessoas em situação de rua existem e que, regra geral, ocupam os logradouros públicos das cidades brasileiras para o fim de moradia. Essas pessoas "percebem o espaço público como seu espaço privado de moradia" como explica Silveira $(2009$, p. 41). Essa realidade um tanto quanto chocante e revoltante, é mais grave do ponto de vista dos direitos humanos. A triste verdade é que esse segmento populacional é praticamente inexistente aos olhos da coletividade, porque o estigma social que sofrem é tão agressivo que faz simplesmente a sociedade "apagar" tais pessoas do seu campo de visão. A situação se agrava porque muitas atrocidades são sofridas pelas pessoas em situação de rua.

A expressão situação de rua traduz bem as condições de 'fragilidade', 'incerteza', 'provisoriedade' e 'precariedade’ nas quais vivem indivíduos e grupos sem-lugar que, regra geral, não utilizam "moradia convencional regular". Aliada a essas condições, tem-se um processo de produção social e afirmação de identidades que diz o lugar, o papel ou a posição da pessoa na sociedade, suscitando, também, múltiplos sentimentos de pertencimento e lugar no mundo. É o que acontece com as pessoas em situação de rua, as quais são atribuídas representações capazes de enquadrá-las em uma identidade subversiva, uma diferença indesejável, profundamente depreciativa, que frustra as expectativas de normalidade social e que, aos olhos da sociedade, serve para desacreditar a pessoa que a possui. Esse processo opressor é denominado de estigma por Goffman (2008), categoria de análise importante para se pensar as relações sociais entre as pessoas ditas 'normais' e os indivíduos e grupos em situação de vulnerabilidade socioeconômica.

O estigma é a representação desse processo de marginalização. É uma 'marca', um 'rótulo', um 'disfarce', uma espécie de 'acobertamento' da identidade real do sujeito, fornecendo à pessoa que o porta a característica de periculosidade, um reconhecimento perverso de inferioridade frente aos demais, e que, para garantir a ordem social acaba funcionando como justificativa para as práticas estigmatizadoras, como se verá ao longo do texto.

Infelizmente, as representações sociais a respeito das pessoas em situação de rua as descrevem a partir de inúmeras denominações pejorativas, desqualificam-nas como mendigos, malandros, perigosos, marginais, subversivos etc. Do ponto de vista dos direitos humanos, esse tratamento baseado na subalternização e desqualificação desses sujeitos, remete, necessariamente ao debate sobre o direito à cidade, à uma vida na cidade que tenha por 
centralidade a pessoa e inclua a superação do fenômeno da segregação social em suas diferentes formas e dimensões. Enfim, nas palavras de Lefebvre (2013, p. 134), o direito à cidade

[...] se manifesta como a forma superior dos direitos: direito à liberdade, à individualização na socialização, ao habitat e ao habitar. O direito à obra (à atividade participante) e o direito à apropriação (bem distinto do direito à propriedade) estão implicados no direito à cidade.

Percebe-se, portanto, que qualquer abordagem do direito à cidade deve considerar a dimensão política da cidade enquanto espaço de usufruto pleno e equitativo por todos os seus habitantes. Essa concepção dialoga com o Estatuto da Cidade (Lei n. 10.257/2001) que inovou o ordenamento jurídico pátrio ao adotar a expressão "cidade sustentável" como direito difuso, transindividual e indisponível dos seus habitantes, postulando pelo desenvolvimento urbano de tornar as cidades mais justas, humanas e democráticas, com condições dignas de vida.

Nessa perspectiva, este artigo pretende refletir a respeito do processo deliberado e sistemático que invisibilisa as pessoas em situação de rua no Brasil, discutindo o quanto isso é pernicioso à luz dos direitos humanos, porque subtrai-lhes o gozo do direito à cidade.

Para a realização desse trabalho, utilizou-se metodologicamente a pesquisa bibliográfica que envolveu fundamentalmente a análise de produções científicas, visando melhor compreensão a respeito do processo de produção social e afirmação de identidade subversiva às pessoas em situação de rua e temáticas correlatas como o fenômeno população em situação de rua, vulnerabilidade socioeconômica desse segmento social, direito fundamental à cidade. Utilizou-se, também, a pesquisa documental quando se recorreu a inúmeros diplomas jurídicos pertinentes, notadamente à Constituição da República e ao Estatuto da Cidade, principal março jurídico atinente ao direito à cidade. Associado a isso, fez-se necessário o uso da pesquisa qualitativa enquanto perspectiva de abordagem da temática e objeto de estudo.

A vulnerabilidade tem o significado de tornar grupos sociais passíveis de desrespeito aos direitos fundamentais pertinentes a qualquer pessoa, tais como a vida, a liberdade, a alimentação, a educação, o trabalho, enfim, ao de usufrui das condições básicas para a vida digna, qualidade que esse núcleo de direitos inspira. A consequência disso para um grupo social é a de fragilizá-lo diante de grupos sociais dominantes, assim posicionados por desfrutarem daqueles direitos, não raramente, em doses de teor elevado. Em decorrência dessa notória desigualdade, com perspectivas de se tornar abissal, cada vez mais, surgem grupos vulneráveis, com tendência a se cristalizarem nessa condição. No rol desses grupos, que têm aqueles direitos maltratados ou obscurecidos, estão os moradores em condição de rua. 


\section{FENÔMENO POPULAÇÃO EM SITUAÇÃO DE RUA: AMÁLGAMA DE FATORES NEGATIVOS}

O Decreto Federal $n^{0} 7.053$, de 23 de dezembro de 2009, que institui a Política Nacional para a População em Situação de Rua e seu Comitê Intersetorial de Acompanhamento e Monitoramento, em seu Parágrafo Único, do artigo $1^{\circ}$, define a população em situação de rua como

[...] grupo populacional heterogêneo que possui em comum a pobreza extrema, os vínculos familiares interrompidos ou fragilizados e a inexistência de moradia convencional regular, e que utiliza os logradouros públicos e as áreas degradadas como espaço de moradia e de sustento, de forma temporária ou permanente, bem como as unidades de acolhimento para pernoite temporário ou como moradia provisória. (Grifos acrescidos).

Observa-se que o conceito de população de rua é formado, dentre outras, pela característica de "inexistência de moradia convencional". Há consenso na literatura corrente e especializada de que as pessoas em situação de rua constituem um segmento social extremamente heterógeno, apresentando especificidades em sua composição, com múltiplas subjetividades de indivíduos e singularidades internas, com perfis socioeconômicos bastante diversificados, mas esse público tem em comum a condição de pobreza extrema, o absoluto despojamento material, o extremo da exclusão social, o elevado grau de miserabilidade e sofre com o risco social, resultado de tormentosas desigualdades sociais, encontrando-se, assim, imerso em sistemáticas carências de oportunidades e vive em condições de vulnerabilidades socioeconômicas associadas e cumulativas, correspondendo, portanto, a um verdadeiro fenômeno social.

O fato, tão inegável quanto chocante, é o de que as pessoas em situação de rua estão nos logradouros de praticamente todas as cidades brasileiras. Contudo, esse fenômeno carece da devida atenção por parte do Poder Público, que se utiliza das mais variadas estratégias para invisibilizá-lo. Nesse contexto, é primária a necessidade de dar visibilidade ao fenômeno população em situação de rua, disseminando densa e crítica reflexão sobre esse segmento social, o que demanda trazê-lo para o centro do debate sociopolítico como tarefa ética inadiável e fundamental, dando vazão às questões atinentes às agruras socioeconômicas e políticas que as 
pessoas em situação de rua enfrentam, tema cujo estudo, ainda que extremamente relevante, carece de compreensão sistêmica e publicização.

Em geral, a população em situação de rua é vista pela sociedade como um grupo que oferece risco, e não como um segmento que se encontra em risco. Principalmente quando confrontada com os interesses econômicos, essas pessoas são vistas como um problema, enquanto, na verdade, o problema é a situação de rua. É imperioso, desse modo, com foco nos direitos humanos, alterar a abordagem social do problema enfrentado pela população em situação de rua como um risco à sociedade, para a condição, na verdade, de vítima, muitas vezes, da própria sociedade. Faz-se necessário, portanto, trocar as lentes, mudar de perspectiva, focando na situação de risco e em seus múltiplos fatores e condicionantes, ao invés de focar na ameaça à ordem pública que supostamente as pessoas em situação de rua representam.

Em nível nacional, as condições de vida das pessoas em situação de rua revela-se como um das mais duras manifestações da extrema pobreza material, um aspecto das desigualdades sociais. Trata-se de significativa parcela da sociedade inserida no contexto de risco social, marginalizada e excluída de acesso aos direitos fundamentais, notadamente à saúde, educação, trabalho, alimentação e moradia, que forma a base dos direitos sociais, configurando, assim, incontestável violação à dignidade e aos direitos humanos e fundamentais desses sujeitos.

Na maioria das vezes, esses sujeitos perambulam pelas ruas, dormem nos logradouros públicos e privados gelados sob o rigor do inverno ou do calor sufocante e torturante do verão, se encontrando, assim, em condições extremamente desfavoráveis em relação às outras pessoas. São pessoas em situação de vulnerabilidade frente à maior fragilidade social que apresentam perante outros grupos da sociedade, sendo vítimas de adversidades e acabam se tornando “invisíveis" aos olhos da coletividade. O que poucos sabem é o preconceito que sofrem essas pessoas, que estão suscetíveis à inúmeras formas de violência, maus tratos e, principalmente, ao desprezo e abandono da sociedade e do Poder Público. É uma luta diária por sobrevivência. E o que é pior: as pessoas em situação de rua geralmente não têm consciência de que possuem os mesmos direitos e deveres dos seus pares sociais. A pessoa que está nessa situação torna-se um "excluído", um "invisível”, impossibilitado de partilhar de uma vida pessoal e profissional formal, resultando, certamente, em sérios prejuízos à sociedade. O fato de existirem indivíduos nessa situação faz com que exista uma desigualdade relevante na sociedade.

Frente a essa radiografia do horror de um segmento social (in)visível que vive as agruras como despojamento material, impossibilidade de acesso a direitos básicos, intempéries, insalubridade, insegurança e outras formas de violência, não há dúvida de que a população em 
situação de rua constitui um grupo vulnerável, como deflui da conceituação ofertada por Silva (2010, p. 141):

Os grupos vulneráveis são os grupamentos de pessoas que, não obstante terem reconhecido seu status de cidadania, são fragilizados na proteção de seus direitos e, assim, sofrem constantes violações de sua dignidade: são, por assim dizer, tidos como invisíveis para a sociedade, tão baixa é a densidade efetiva dessa tutela.

Socialmente, as pessoas em situação de rua são "descartáveis urbanos" (ADORNO, 2004) ou "refugo humano" (BAUMAN, 2005), um ônus social e um dos pontos paradigmáticos dos direitos humanos, porque viver em condições de extrema fragilidade social significa, do ponto de vista da fruição de seus direitos, estar privado de tudo ou pelo menos encontram maiores obstáculos à efetivação de direitos fundamentais prestacionais. Sobre esta situação Arendt (1989) apresenta a existência de um direito a ter direitos, isto é, o direito de pertencer a uma comunidade organizada, no entanto "só em uma humanidade completamente organizada, a perda do lar e da condição política de um homem pode equivaler à sua expulsão da humanidade.” (ARENDT, 1989, p. 330).

Em 2008, o Ministério de Desenvolvimento Social e Combate à Fome (MDS), realizou a Pesquisa Nacional sobre a População em Situação de Rua ${ }^{3}$, estabelecendo, para tanto, como universo os municípios com população igual ou superior a 300.000 (trezentos mil) habitantes, as capitais de estado e o Distrito Federal. A dita pesquisa contabilizou 31.922 (trinta e um mil, novecentas e vinte e duas) pessoas adultas vivendo em "calçadas, praças, rodovias, parques, viadutos, postos de gasolina, praias, barcos, túneis, depósitos e prédios abandonados, becos, lixões, ferro-velho ou pernoitando em instituições (albergues, abrigos, casas de passagem e de apoio e igrejas)" (BRASIL, 2008).

A partir dessa estimativa, foi possível auferir uma diversidade de dados relativos ao perfil socioeconômico e demográfico atinentes às pessoas em situação de rua. A pesquisa trouxe

\footnotetext{
${ }^{3}$ A Pesquisa Nacional da População em Situação de Rua partiu da premissa de que há tendência de maior concentração de pessoas em situação de rua nos municípios mais populosos e nas capitais dos estados. Estes concentram maiores recursos, serviços e possibilidades de toda ordem, tanto por parte da sociedade em geral como por parte do poder público. Assim, essas localidades tendem a ser mais procuradas por pessoas em situação de vulnerabilidade que necessitam de oportunidades de emprego e procuram condições mais favoráveis para a sua sobrevivência. Nesse sentido, estabeleceu-se como universo da pesquisa os municípios com população igual ou superior a 300.000 (trezentos mil) habitantes, as capitais de estado e o Distrito Federal. Foram excluídos do universo os municípios que realizaram ou estavam desenvolvendo levantamento semelhante (Belo Horizonte-MG, São Paulo-SP, Recife-PE e Porto Alegre-RS). Assim, foram selecionados 71 municípios, sendo 23 capitais independentes do tamanho populacional e 48 municípios com população igual ou superior a 300.000 habitantes. Em todas as cidades selecionadas foi realizado censo das pessoas em situação de rua, por meio da aplicação de um questionário reduzido, e pesquisa amostral que investigou um conjunto maior de questões em cerca de $10 \%$ das pessoas entrevistadas em cada município.
} 
em seu bojo o ineditismo censitário, porque esta população não vinha sendo incluída nos censos demográficos brasileiros que possuem como base o domicílio em sua metodologia de contagem. Essa primeira quantificação traçou oficialmente o perfil ${ }^{4}$ dessa parcela da população brasileira, permitindo, assim, quantificar e caracterizar socioeconomicamente melhor esse público. A realização do censo foi importante porque é uma maneira de reconhecer que o fenômeno existe e que representa um imenso desafio a ser enfrentado pelo Poder Público.

Por consequência, a dita pesquisa cumpre atualmente um papel sociopolítico significativo por seu ineditismo e, primordialmente, por trazer à baila quantitativamente e qualitativamente aspectos socioeconômicos e demográficos da população em situação de rua, revelando, em grande medida, uma das feridas sociais da contemporaneidade brasileira: o fenômeno da pobreza material absoluta experimentado por um contingente substancial da população que sobrevive em situações bastante precárias, sub-humanas, e até mesmo não dignificantes com a condição de seres humanos.

Deve-se abordar, desse modo, sobre a população em situação de rua como um fenômeno complexo e multifacetado, o qual exige um conjunto de olhares para sua compreensão e enfrentamento, posto que, infelizmente, essa problemática social não tem merecido a devida atenção por parte dos entes federativos e da sociedade em geral. A

\footnotetext{
${ }^{4}$ Os dados da Pesquisa Nacional sobre a População em Situação de Rua identificou: a) que os principais motivos que levaram essas pessoas à situação de rua foram o alcoolismo/drogas $(35,5 \%)$, o desemprego $(29,8 \%)$, as desavenças com pai/mãe/irmãos $(29,1 \%)$, perda de moradia (20,4\%), separação/decepção amorosa (16,1\%); b) $82 \%$ eram do sexo masculino; c) 53\% com faixa etária de idade entre 25 e 44 anos; d) $67 \%$ se autodeclararam negros; e) $74 \%$ sabiam ler e escrever, $17,1 \%$ não sabiam escrever e $8,3 \%$ apenas assinavam o próprio nome, sendo que a imensa maioria não estudava (95\%); f) 69,6\% costumava dormir na rua, sendo que 48,4\% estava há mais de dois anos dormindo na rua ou em albergue, e cerca de 30\% dormia na rua há mais de 5 anos; $22,1 \%$ costumava dormir em albergues ou outras instituições; g) 59\% dos entrevistados afirmaram ter profissão, principalmente relacionada à coleta de material reciclável, construção civil, ao comércio, ao trabalhado doméstico e ao serviço de mecânica, sendo que do universo dos que afirmaram ter profissão, 70,9\% exerciam alguma atividade remunerada, e a maioria $(52,6 \%)$ declarou receber entre $\mathrm{R} \$ 20,00$ e $\mathrm{R} \$ 80,00$ semanais, pelos trabalhos desenvolvidos; $\mathrm{h}$ ) apenas $15,7 \%$ pediam dinheiro como principal meio para a sobrevivência; i) $29,7 \%$ dos entrevistados afirmaram ter algum problema de saúde, como hipertensão $(10,1 \%)$, problema psiquiátrico/mental $(6,1 \%)$, HIV/Aids $(5,1 \%)$ e problemas de visão/cegueira $(4,6 \%) ; \mathrm{j})$ a maioria dos entrevistados $(79,6 \%)$ conseguia fazer ao menos uma refeição ao dia; $\mathrm{k}$ ) em se tratando da participação social, $95,5 \%$ declararam não participar de qualquer movimento social ou associativismo, sendo que apenas $2,9 \%$ indicaram essa participação; 1 ) no que se refere ao acesso à documentação civil e serviços públicos, $24,8 \%$ não possuíam qualquer documento de identificação, o que dificulta a obtenção de emprego formal, o acesso aos serviços e programas governamentais e o exercício da cidadania; 61,6\% não possuíam título de eleitor e, portanto, estavam impedidos de exercerem o direito de cidadania elementar que é o voto; $59,9 \%$ sem carteira de trabalho; $57,4 \%$ não possuíam CPF; $49,2 \%$ não possuíam certidão de nascimento ou de casamento e 40,7\% sem carteira de identidade; m) $88,5 \%$ não eram atingidas pela cobertura dos programas governamentais, sendo que dos que declararam receber algum benefício, 3,2\% recebiam aposentadoria, 2,3\% estavam inseridos no Programa de Transferência de Renda Bolsa Família e 1,3\% recebiam o Benefício de Prestação Continuada; n) $54,5 \%$ das pessoas entrevistadas teriam sofrido algum tipo de discriminação, principalmente por meio do impedimento de suas entradas em estabelecimentos comerciais, shopping center, transporte coletivo, bancos, algum órgão público, de serem atendidos nos órgãos de saúde, além do impedimento na retirada de documentos.
} 
preocupação do Poder Público com esse segmento populacional é recente ${ }^{5}$ e consequência de lutas sociais ocorridas, particularmente, na última década.

\section{PRODUÇÃO SOCIAL DE IDENTIDADES SUBVERSIVAS PARA A POPULAÇÃO EM SITUAÇÃO DE RUA}

Às pessoas em situação de rua são atribuídas identidades preconceituosas, que sustentam a marginalização em que vivem na sociedade brasileira. As identidades e representações para esta população são marcadas por uma relação dialética de inclusão/exclusão, elaborando o lugar social de sujeitos desapropriados de direitos e condições dignas de vida. Existem parâmetros compartilhados socialmente para explicar porque o "outro" é considerado diferente, "estranho", a partir da comparação de uma pessoa (ou um grupo de pessoas) com um padrão definido como "ideal” pelo grupo dominante. Salienta Goffman (2008, p. 11): "A sociedade estabelece os meios de categorizar as pessoas e o total de atributos considerados como comuns e naturais para os membros de cada uma dessas categorias". São ideias e atitudes arbitrárias e arraigadas socialmente, consubstanciadas em relações desiguais entre as pessoas nominadas "normais" e "anormais", "iguais" e "diferentes".

Daí ser imperioso afirmar que as pessoas com deficiência são vítimas de estigmas ${ }^{6}$, pois Goffman diz que quando as marcas pelas quais as pessoas passam a ser identificadas socialmente são negativas, ali está o estigma, que produz uma quebra na relação social entre os portadores de estigmas e as outras pessoas. As expectativas que os estigmas indicam são tidas como certas e reduzem a identidade do estigmatizado à marca: essa condição suprime seus

\footnotetext{
${ }^{5} \mathrm{O}$ desinteresse do Estado pelas pessoas em situação de rua reflete a contradição com que a opinião pública trata o tema, ora com compaixão e até assistencialismo, ora com repressão, repulsa e indiferença. Cita-se que todos os serviços voltados para essa população advindos do poder público estão na área da política de assistência social, o que sobrecarrega essa área e torna as ações frágeis e vulneráveis, pois não respondem às demandas dessa população na sua totalidade. Malgrado não seja um fenômeno novo no Brasil, percebe-se que apenas há alguns poucos anos o poder público passou a demonstrar uma incipiente preocupação com as pessoas em situação de rua, seja através da elaboração de normas, seja por meio de ações concretas.

${ }^{6} \mathrm{O}$ estigma encerra uma forte desaprovação de características reais, comportamentos e crenças pessoais ou grupais que aparentemente vão contra normas culturais e padrões e exigências impostas rigorosamente e aceitas por diferentes sociedades, em tempos e espaços diversos. Nessa atmosfera, ao discorrer a respeito da construção da "identidade social virtual", Goffman, afirma que estigma é uma visão ou avaliação depreciativa imputada aos atributos ou características individuais ou grupais, que coloca o outro (o diferente, o estranho) em uma posição de descrédito frente aos demais indivíduos ou segmentos sociais; é um valor negativo e falsamente cominado à condição real que alguém apresenta, que, por princípio, teria uma estimação diferente, menor, frente as demais pessoas e grupos (GOFFMAN, 2008, p. 12-14). É um rótulo, um sinal, uma marca; por exemplo, referir-se à pessoa com deficiência como "retardada", esta passa a ser estigmatizada, sendo reconhecida, a partir de então, pelos aspectos "negativos" associados a esta marca, sinal ou rótulo, que confere ao indivíduo, assim, uma identidade social e pessoal estereotipada.
} 
outros atributos, outras qualidades, impossibilitando que ele se mostre algo além do que sua marca indica (GOFFMAN, 2008. p.14). Para conceituar estigma, Goffman parte do princípio de que a sociedade fornece uma série de normas de categorizações e hierarquizações específicas para os sujeitos e espaços sociais, criou-se uma série de identidades e preconcepções sobre os sujeitos e "baseando-nos nessas preconcepções, nós as transformamos em expectativas normativas, em exigências apresentadas de modo rigoroso" (GOFFMAN, 2008. p.12). Essas preconcepções são percebidas socialmente através de marcas simbólicas, elementos de significação, que alocam os sujeitos em determinadas posições que aludem a padrões de comportamento e previsão de ação. O estigma cria identificações e se consolida na relação entre a identidade social virtual e a identidade social real. Essa relação se estabelece numa dinâmica perversa, como de deflui da lição de Goffman (2008, p. 12-13):

\begin{abstract}
deixamos de considerá-lo [o portador do estigma] como uma criatura comum e total, reduzindo-o a uma pessoa estragada e diminuída. Tal característica é um estigma, especialmente quando o seu efeito de descrédito é muito grande (...) e constitui uma discrepância específica entre a identidade virtual e a identidade real. (...) O termo estigma, portanto, será usado em referência a um atributo profundamente depreciativo, mas o que é preciso, na realidade, é uma linguagem de relações e não de atributos. Um atributo que estigmatiza alguém pode confirmar a normalidade de outrem, portanto ele não é, em si mesmo, nem honroso nem deshonroso."
\end{abstract}

O mundo é, assim, lexicalizado de maneira a legitimar a exclusão e a ideia de não pertencimento das pessoas em situação de rua. Os termos "trecheiros, "andarilhos, "mendigos", "pedintes", “flanelinhas", "bandidos", “noiados", “marginais”, "ladrões”, “criminosos", "viciados", "vagabundos", “malandros", “doentes", "sujos”, "preguiçosos”, “acomodados", "vadios", "loucos", “drogados", “transgressores", "potenciais contaminadores”, dentre outras expressões instituídas e compartilhadas socialmente, funcionam, na prática, como estigmas. Essas alcunhas negativas estão ligadas a "esmola", "criminalidade", "tráfico de drogas", acentuando a ideia de violência e de vadiagem, ligadas, assim, a diversas atividades consideradas ilegais, categorização das pessoas, ligando-as a um fatores negativos.

Nesse ponto, ocorre o que é denominado identificação, ou seja, as pessoas em situação de rua são definidas principalmente em termos do que supostamente são. Por meio desses itens lexicais, constrói-se o discurso de que a vida na rua seria uma forma mais fácil, dentre outras opções que a pessoa poderia realizar, e que seria portanto uma escolha pelo menor esforço, não uma situação em que a dignidade da pessoa é posta em risco. Cria-se o estigma da pessoa em situação de rua baseada na ética do trabalho, como "inaptas", "fracassados”, "incapazes", "vagabundos", "fora do padrão conferido pelo sistema", "indivíduos supérfluos e 
desnecessários ao mundo de produção" etc. É o discurso da responsabilização pessoal pelas escolhas, destacado no campo semântico da liberdade. As pessoas em situação de rua são apontadas como as únicas responsáveis por estarem vivendo nessa condição, como se gozassem, na realidade, de capacidade para optar por essa forma de vida despida de direitos básicos: moradia, alimentação, saúde, educação, trabalho etc. Ao atribuírem a responsabilidade por si mesmos apenas aos indivíduos a partir de uma falsa noção de liberdade, a responsabilidade coletiva e o bem-estar social são esquecidos, e prevalece a ideologia liberalista-individualista da higienização e da naturalização de categorizações e hierarquizações.

A identidade social do estigmatizado é, via de regra, negativa e degradada com a função de diminuir valorativamente sujeitos frente ao sujeito dito normal. Extrai-se da noção de estigma concebida por Goffman que o indivíduo que convive com a marca designada estigma é reduzido a uma pessoa estragada e diminuída e que, por consequência, não se acredita que seja humano por completo.

A concepção goffmaniana de estigma é valiosa posto que denuncia a relação na qual se institui extremos entre um sujeito dito normal e um outro indivíduo depreciado socialmente, marginalizado, não-humano. Interessante é perceber que, segundo Goffman, o padrão de vida ideal, os valores éticos e morais e as experiências vivenciadas por indivíduos ditos normais, acabam servindo de referência à identidade do estigmatizado, que age e se orienta na sociedade a partir deles. Com efeito, essa questão reside no fato de que "o indivíduo estigmatizado tende a ter as mesmas crenças sobre identidade que nós temos [sujeitos normais]; isso é um fato central. Seus sentimentos mais profundos sobre o que ele é podem confundir a sua sensação de ser uma "pessoa normal", um ser humano como qualquer outro" (2008, p. 16). Assim, de acordo com os estigmas produzidos e veiculados pela sociedade para tais sujeitos, avaliam seus pares e se avaliam também, como dizem Vieira, Bezerra e Rosa (2004, p. 100): “o morador de rua assume de forma extremamente rígida o estigma lançado sobre si, utilizando os olhos da sociedade para avaliar sua condição social”. A negação da condição de sujeito resulta na internalização de situações de sofrimentos, que repercute na formação da identidade dessas pessoas. Esse processo de introjeção de representações negativas que legitimam e naturalizam a forma de tratá-las, desembocam na construções de sensações de culpabilidade, vergonha e diminuição social.

Reafirma-se, assim, a existência de um processo de produção social de identidades, capaz de diferenciar as posições ou lugares de cada grupo nessa sociedade, ocasionando, por 
assim dizer, também múltiplos sentimentos de pertencimento e lugar no mundo. A identidade perversa construída a respeito das pessoas em situação de rua cristaliza-se com tanta intensidade que a "metamorfose da identidade" (CORRÊA, 2009. p. 81) parece sem força capaz de imprimir qualquer reversão nesse quadro nefasto ou mesmo acenar com possibilidade de provocar reflexões, (re)inventar maneiras ou condições adequadas de emancipação social mediante a garantia da autonomia, fator ou pedra fundamental para o exercício de direitos.

\section{PESSOAS EM SITUAÇÃo DE RUA E O DIREITO À CIDAde QUE LHES É NEGADO}

O estudo sobre o direito à cidade não é recente e nem iniciou com a doutrina jurídica, constituindo-se objeto de análise pioneira pelo sociólogo e filósofo francês Henri Lefebvre, quando do lançamento de sua obra seminal "Le droit à la ville”, publicada em 1968, a qual esbouça ideias essenciais e intrigantes sobre o tema, que convergem na compreensão de que esse direito corresponde à produção e fruição coletiva da cidade. O ideário humanista do direito à cidade difundiu-se na literatura especializada internacional e nacional ao longo das últimas décadas e hoje não são poucos os autores que se lançam ao debate sobre o assunto.

No âmbito internacional, o delineamento mais preciso a respeito do entendimento sobre o direito à cidade começou a ser elaborado a partir de 2001, no I Fórum Social Mundial (Porto Alegre/RS/Brasil), quando movimentos sociais e organizações não-governamentais de todo o mundo, articulados com a luta pela reforma urbana, tiveram a iniciativa de elaborar um documento que representasse a materialização legal desse direito. Os debates tiveram continuidade no II Fórum Social Mundial (Porto Alegre/RS/Brasil, 2002) e no Fórum Social das Américas (Quito, 2004) e no Fórum Mundial Urbano (Barcelona, 2004), sendo que, finalmente, no Fórum Social Mundial realizado em 2005 na cidade de Porto Alegre - RS/BR, obteve-se a redação definitiva e aprovação da Carta Mundial pelo Direito à Cidade $^{7}$, que se

\footnotetext{
${ }^{7}$ A Carta condensa valores e princípios amparados em diversos tratados internacionais e na Constituição da maioria dos países democráticos, reúne uma síntese de direitos ambientais, sociais, econômicos e culturais e constitui instrumento dirigido a contribuir com as lutas urbanas e com o processo de reconhecimento no sistema internacional dos direitos humanos do direito à cidade. Disponível em: http://www.forumreformaurbana.org.br/index.php/documentos-do-fnru/41-cartas-e-manifestos/133-cartamundial-pelo-direito-a-cidade.html. Acesso em: 10 mar. 2016. Cumpre ressaltar que, em 2005, durante a realização do Fórum Social Mundial em Porto Alegre - RS, o governo brasileiro, por intermédio do Ministério das Cidades, se comprometeu formalmente com o teor da Carta Mundial do Direito à Cidade.
} 
traduz em um esforço importante de reunir diversas normas sobre direitos econômicos, sociais, culturais e ambientais.

A Carta revela o compromisso das autoridades públicas internacionais e locais no sentido de garantir o respeito e a proteção dos direitos humanos para todos os habitantes das cidades, principalmente para as pessoas que se encontram em estado de vulnerabilidade ${ }^{8}$, e tem o potencial de servir de importante instrumento internacional de auxílio a entidades públicas e privadas, para melhor atuação em prol de cidades mais justas, democráticas, sustentáveis e humanas. Em face de sua relevância sociopolítica, compartilha-se parte essencial da definição estatuída no artigo I, 2:

Como o usufruto equitativo das cidades dentro dos princípios de sustentabilidade, democracia e justiça social. É um direito coletivo dos habitantes das cidades, em especial dos grupos vulneráveis e desfavorecidos, que lhes confere legitimidade de ação e organização, baseado em seus usos e costumes, com o objetivo de alcançar o pleno exercício do direito à livre autodeterminação e a um padrão de vida adequado. O Direito à Cidade é interdependente a todos os direitos humanos internacionalmente reconhecidos, concebidos integralmente, e inclui, portanto, todos os direitos civis, políticos, econômicos, sociais, culturais e ambientais que já estão regulamentados nos tratados internacionais de direitos humanos. [...].

Depreende-se dessa definição que o direito à cidade é reconhecido como direito difuso, que reflete a diversidade da relação dinâmica entre pessoas e espaços, sendo indivisível e de titularidade indeterminada, lócus por excelência de incremento de vários direitos fundamentais, tais como moradia, lazer, trabalho, educação, saúde, ir e vir, entre outros. A garantia desse direito credita ao Poder Público o papel de concretizar as funções sociais da cidade em favor de todos os habitantes, particularmente dos segmentos sociais vulneráveis, tornando-se uma questão intrínseca ao planejamento da cidade e à sua sustentabilidade, compreendida de forma ampla e imbricada à qualidade de vida de todos os seus moradores. Ao focar nos grupos sociais ou indivíduos que se encontram em condições de vulnerabilidade socioeconômica,

\footnotetext{
${ }^{8}$ O Artigo II, item 4 (PROTEÇÃO ESPECIAL DE GRUPOS E PESSOAS VULNERÁVEIS) da Carta Mundial pelo Direito à Cidade, assim estabelece: "4.1. Os grupos e pessoas em situação de vulnerabilidade têm direito a medidas especiais de proteção e integração, de distribuição de recursos, de acesso aos serviços essenciais e de não-discriminação. Para os efeitos dessa Carta se consideram vulneráveis as pessoas e grupos em situação de pobreza, em risco ambiental (ameaçados por desastres naturais), vítimas de violência, com incapacidades, migrantes forçados, refugiados e todo grupo que, segundo a realidade de cada cidade, esteja em situação de desvantagem em relação aos demais habitantes. Nestes grupos, por sua vez, serão objeto prioritário de atenção os idosos, as mulheres, em especial as chefes de família, e as crianças. 4.2. As Cidades, mediante políticas de afirmação positiva aos grupos vulneráveis devem suprir os obstáculos de ordem política, econômica e social que limitam a liberdade, equidade e de igualdade dos cidadãos(ãs), e que impedem o pleno desenvolvimento da pessoa humana e a participação efetiva na organização política, econômica, cultural e social da cidade". (Grifei).
} 
evidenciando, assim, a sustentabilidade, a democracia, a equidade e a justiça social, a Carta Mundial pelo Direito à Cidade enfatiza claramente o valor de uso da cidade preconizado por Lefebvre, demarcando a necessidade de reverter a predominância dos poderes econômicos e financeiros em detrimento da função social da cidade e da função socioambiental da propriedade.

Ainda na perspectiva internacional, merece destaque o V Fórum Urbano Mundial ${ }^{9}$ (FUM 5), do Programa das Nações Unidas para os Assentamentos Humanos (ONUHABITAT $^{10}$ ), realizado em março de 2010 na cidade do Rio de Janeiro, quando discutiu-se o tema "O Direito à Cidade: Unindo o Urbano Dividido". Esse evento marcou, de certa forma, mais um patamar de discussões de temáticas urbanísticas visando firmar a noção de direito à cidade e consignar a urbanização sustentável na pauta da elaboração de políticas públicas globais, nacionais e locais.

Em nível do direito pátrio, o direito à cidade ganhou contornos normativos na Constituição Federal de 1988, sendo alçado à ordem jurídica na condição de direito fundamental. Nessa qualidade, o direito à cidade é um direito síntese, congregando um catálogo de inúmeros outros direitos também fundamentais como moradia, saneamento, transporte coletivo etc. Não há qualquer dúvida de que a finalidade precípua da Política Urbana disposta no texto constitucional visa a democratização das funções sociais da cidade e da propriedade em proveito de seus habitantes, em prol do bem-estar e qualidade de vida de todos. Veja-se:

Art. 182. A política de desenvolvimento urbano, executada pelo Poder Público municipal, conforme diretrizes gerais fixadas em lei, tem por objetivo ordenar o pleno desenvolvimento das funções sociais da cidade e garantir o bem-estar de seus habitantes.

\footnotetext{
${ }^{9}$ Considerado o principal evento para discussões urbanísticas do mundo, o FUM reúne agentes governamentais, representantes do setor privado e da sociedade civil, para pensar soluções e políticas que mitiguem os problemas gerados pela rápida urbanização nas diferentes regiões do globo. Foi criado pela ONU para analisar um dos problemas mais prementes do mundo de hoje: a rápida urbanização e seu impacto sobre as comunidades, cidades, economias, as alterações climáticas e políticas. Desde a primeira reunião em Nairóbi, no Quênia, em 2002, o Fórum tem crescido em tamanho e estatura, sendo realizado em Barcelona (2004), Vancouver (2006), Nanquim (2008), Rio de Janeiro (2010), Nápoles (2012) e Medellín (2014). Nanjing (2016).

10 “Com sede em Nairóbi, Quênia, a organização é a encarregada de coordenar e harmonizar atividades em assentamentos humanos dentro do sistema das Nações Unidas, facilitando o intercâmbio global de informação sobre moradia e desenvolvimento sustentável de assentamentos humanos, além de colaborar em países com políticas e assessoria técnica para enfrentar o número crescente de desafios enfrentados por cidades de todos os tamanhos." Disponível em: https://nacoesunidas.org/agencia/onu-habitat/. Acesso em: 20 abr. 2016. A ONUHABITAT foi estabelecida em 1976 e constitui-se a principal agência da ONU na área habitacional e concentra esforços em assuntos relacionados com cidades sustentáveis e implementação projetos especiais focados nos assentamentos precários, visando a construção de moradias dignas. A Primeira Conferência da ONU sobre Assentamentos Humanos (Habitat I), aconteceu em Vancouver - Canadá - 1976; a Segunda (Habitat II), aconteceu em Istambul - Turquia - 1996; e a Assembleia Geral da ONU decidiu que em outubro de 2016 Quito, no Equador, será a sede da cúpula da Terceira Conferência (Habitat III).
} 
A Lei $\mathrm{n}^{\circ}$ 10.257/2001, designada Estatuto da Cidade, veio ao encontro da necessidade de concretizar aqueles preceitos constitucionais, conferindo-lhes corporeidade normativa e disciplinando a execução da política urbana, com normas de ordem pública e interesse social que regulam o uso da propriedade urbana em prol do bem coletivo, da segurança e do bemestar dos cidadãos, bem como do equilíbrio ambiental (art. $1^{\circ}$, parágrafo único).

Trazendo contornos mais claros ao direito à cidade previsto na Constituição, o art. $2^{\circ}$ do Estatuto da Cidade, enuncia a garantia do direito a cidades sustentáveis, entendido como “o direito à terra urbana, à moradia, ao saneamento ambiental, à infra-estrutura urbana, ao transporte e aos serviços públicos, ao trabalho e ao lazer, para as presentes e futuras gerações”, de onde imediatamente sobressai a noção de que tal direito está intrinsecamente relacionado à implementação de outros direitos de caráter individual e social no âmbito da cidade.

O Estatuto da Cidade, por sua vez, dispensou ao direito à cidade sustentável o status de diretriz geral da política urbana e que se projeta em inúmeros instrumentos de política urbana previstos e regulamentados ao longo do Estatuto, e, trata-se, assim, de normas de ordem pública e interesse social.

\subsection{Como o direito à cidade é subtraído das pessoas em situação de rua?}

O processo de urbanização brasileiro é um fenômeno recente, intenso e produtor de grandes desigualdades socioespaciais, resultando na produção de cidades caóticas, excludentes e fragmentadas, marcadas por carências e despojamento material da quase totalidade de seus habitantes. Segundo dados do IBGE, o Brasil atingiu uma taxa de urbanização de aproximadamente $85 \%$. Nesse cenário, ganha destaque o conceito de direito à cidade, garantindo vida urbana espaços de convívio social, de encontros e de confrontos das diferenças e de interesses de diferentes classes e grupos sociais.

Talvez pelo que foi exposto no tópico anterior, fique evidente que as pessoas em situação de rua não exercem o direito à cidade. Ao vivenciar um processo de negação de direitos dos mais elementares, como o direito à vida, à liberdade, à igualdade e à segurança, bem como o resguardo contra qualquer tratamento desumano ou degradante; e a garantia do acesso às políticas de educação, saúde, alimentação, trabalho, moradia, lazer, previdência social etc. Não apenas negação de direitos, são formas de violência. 
As formas de violência contra a população em situação de rua ocorre desde a violência simbólica, traduzida na indiferença dos transeuntes que diariamente cruzam com esses seres humanos até a mais brutal violação como homicídios. Como afirma Melo (2014, p. 52):

A violência a que estão submetidos vem de todos os lados, dos agentes de segurança pública, como a polícia e a guardas municipais; por parte do Poder Público, por omissão, em muitos casos, pela insuficiência e ineficiência das políticas públicas adotadas, e, por mais contraditório que possa parecer, até mesmo pela ação direta de violação de direitos como o recolhimento dos pertences dessas pessoas; e da própria sociedade civil, que, respaldada por um sistema de exclusão protagoniza casos absurdos, agredindo verbalmente e fisicamente, e, no extremo, buscando exterminálos, como nos relatos de homicídios e tentativas de homicídios - envenenamento, atear fogos, dentre outros.

Entre abril de 2011 e agosto de 2012, o Centro Nacional de Defesa de Direitos Humanos da População em Situação de Rua e Catadores de Material Reciclável - CNDDH, contabilizou mais de 250 homicídios no País, sendo que Minas Gerais liderou o ranking, por conta da sede dessa entidade estar em Belo Horizonte, onde existe também Polícia Civil que recebe muitas denúncias. De acordo com os dados do CNDDH foram 114 casos de hostilização, 58 de ameaças e 48 de humilhação, como pode ser constatado no documento "As vítimas da invisibilidade", disponível em: <http://www.ihu.unisinos.br/entrevistas/518631-as-vitimas-dainvisibilidade-entrevista-especial-com-luana-ferreira-lima-e-maria-do-rosario-de-oliveiracarneiro>. Acesso em: 06 set. 2016.

Outros claros sinais de extermínio e higienização da população em situação de rua são o reconhecimento forçado de pertences e documentos de identificação, um verdadeiro "roubo institucionalizado", configurando exacerbação do poder de polícia, a queima de pessoas quando estão dormindo nos logradouros públicos, apedrejamentos, espancamentos, envenenamentos, violência sexual, psicológica etc. Um caso, dentre as incontáveis agressões a essa população, foi o assassinato do Índio Galdino, há mais de dezessete anos, por cinco jovens de classe média, posteriormente condenados pelo crime. Não menos importante foi o caso da Chacina da Candelária (07.1993), quando oito pessoas entre 11 e 19 anos, que dormiam na praça da igreja da Candelária/RJ, foram executados a tiros por homens que chegaram, à noite, ao local. Três policiais foram condenados.

Outro exemplo é o massacre ocorrido no dia 19 de agosto de 2004, na Praça da Sé em São Paulo, quando sete pessoas em situação de rua foram mortas a pauladas na cabeça, e outros oito ficavam gravemente feridas, sendo que esta data se tornou sinônimo de luta desse grupo social - Dia Nacional de Luta da População de Rua. Apesar da intolerância e barbárie 
verificado no episódio, que ganhou grande repercussão nacional e internacional, no entanto, apesar da cobrança por justiça, feita por organizações de direitos humanos, até hoje, não houve identificação e punição dos culpados.

Sabe-se que a presença de pessoas tendo os logradouros públicos como local habitual de moradia incomoda e causa mal estar em muita gente, gerando ações violentas/agressões oriundas, inclusive e principalmente, dos órgãos oficiais responsáveis pela segurança.

Isso explica porque, por exemplo, o motivo pelo qual parte das políticas insuficientes e ineficientes voltadas para populações em situação de rua, seja da alçada da segurança pública, o que reflete também o pensamento de grupos sociais hegemônicos. Tratam-se de práticas muitas vezes efetivadas com uso de força policial. Portanto, justifica-se a "criminalização da miséria”, como se expressa Wacquant (2003, p. 19) e a repressão mediante a busca por higienização e segregação social, o que significa que, geralmente, a tônica das políticas de segurança pública dirigidas a esse público não são voltadas para a sua proteção, mas sim para a criminalização de seus comportamentos característicos, para o que são utilizadas justificativas eufemistas que pretendem esconder $o$ que se busca de fato, ou seja, a penalização/criminalização da pobreza, potencializando-a. As abordagens truculentas e as medidas higienizantes de intervenção no espaço, visam aos interesses estéticos das cidades, a serviço de grupos econômicos e sociais dominantes.

Em uma análise extensa da jurisprudência cível brasileira, encontra-se número inexpressivo de ações objetivando proteger os direitos das pessoas que vivem em situação de rua, dentre eles, o direito à moradia digna, o que concorre para invisibilisar as demandas desse grupo social vulnerável. Por outro lado, analisando a jurisprudência criminal, nota-se uma nítida criminalização de tais pessoas. Quando se examina a jurisprudência, vê-se que a população em situação de rua somente é vista pela ótica penal. Chega-se ao absurdo de prendê-los por crimes de menor gravidade e deixá-los preso por não terem residência fixa ${ }^{11}$. Sobre tal perspectiva, uma das mais polêmicas e relevantes, Berclaz e Rollo (2014, p. 669-670) se manifestam no seguinte sentido:

Na jurisprudência, a maioria dos julgados relacionados ao "morador de rua" encontrase situada no âmbito criminal. A constatação revela não apenas a invisibilidade do morador perante o sistema, mas, além disso, sua perversidade ao dar-lhes, em maior intensidade, apenas um tratamento, o tratamento repressivo penal, ainda mais num ordenamento que já deveria ter revogado, há muito, a contravenção penal da

${ }^{11}$ Disponível em

http://www.jusbrasil.com.br/jurisprudencia/busca?q=Morador+em+Situa\%C3\%A7\%C3\%A3o+de+Rua. Acesso em: 4 set. 2016. 
vadiagem. Também no tocante a prestações positivas estatais, ou seja, aquelas relacionadas a ações voltadas a garantir direitos sociais da pessoa em situação de rua, a jurisprudência é escassa. [...] A existência de minguada jurisprudência relacionada a prestações positivas estatais à população em situação de rua comprova, de certa forma, que o Sistema de Justiça ainda se revela inatingível para tal contingente.

Por conta disso, não raro pode-se presenciar diversas abordagens e ações de caráter antidemocrático, com perfil higienista-segregacionista, postas, em verdade, com o objetivo de limpar os espaços públicos da população em situação de rua; invisibilizá-la do cotidiano das cidades. A violência a que as pessoas em situação de rua estão submetidas vem de todos os lados, inclusive da própria sociedade civil, que, respaldada por um sistema de exclusão protagoniza casos absurdos.

Só o fato dessas pessoas serem levadas a morarem nas ruas como estratégia de sobrevivência, e com isso estarem expostas à fome, frio, calor e chuvas, corresponde a subtração do direito à cidade. Da mesma forma, o não acesso aos bens e serviços públicos voltados para atender às necessidades básicas, representa violação desse direito.

Soma-se também a essa realidade, a invisibilidade institucional e institucionalizada vivenciada diariamente por essa população, vez que não é nem mesmo incluída nos censos demográficos brasileiros, fundamentalmente porque a coleta de dados populacionais é de base domiciliar. Os dados da Pesquisa Nacional sobre a População em Situação de Rua realizada em 2008 pelo Ministério de Desenvolvimento Social e Combate à Fome (MDS), contabilizou 31.922 (trinta e um mil, novecentas e vinte e duas) pessoas adultas vivendo em "calçadas, praças, rodovias, parques, viadutos, postos de gasolina, praias, barcos, túneis, depósitos e prédios abandonados, becos, lixões, ferro-velho ou pernoitando em instituições (albergues, abrigos, casas de passagem e de apoio e igrejas)" (BRASIL, 2008). Essa informação é uma afronta ao exercício do direito à cidade por esse público.

Igualmente, não deixa de ser negativa do direito à cidade quando, de maneira deliberada e sistemática, o Poder Público impede atendimento às pessoas em situação de rua nos serviços de saúde, educação e assistência social, dada à ausência de comprovação do local de moradia ${ }^{12}$; por conta de discriminações que impedem suas entradas em estabelecimentos comerciais, shopping center, transporte coletivo, bancos etc; ou então, esse público que muitas vezes não possui qualquer documento de identificação (61,6\% não possuíam título de eleitor;

\footnotetext{
12 Em relação ao tema, MDS divulgou o interesse em inserir tal população no Cadastro Único para Programas Sociais do Governo Federal. Notícia disponível em: <http://noticias.portalbraganca.com.br/nacional/nacionalgoverno-vai-incluir-pessoas-em-situacao-de-rua-no-cadastro-unico-de-programas-sociais.php> Acesso em: 06 set. 2016.
} 
59,9\% sem carteira de trabalho; $57,4 \%$ não possuíam CPF; 49,2\% não possuíam certidão de nascimento ou de casamento e 40,7\% sem carteira de identidade), tem seu acesso negado ao mercado de trabalho formal e aos serviços e programas governamentais $(88,5 \%$ afirmaram não receber qualquer benefício, sendo que dos que declararam receber algum benefício, 3,2\% recebiam aposentadoria, 2,3\% estavam inseridos no Programa de Transferência de Renda Bolsa Família e 1,3\% recebiam o Benefício de Prestação Continuada). (BRASIL, 2008).

O texto expos formas silenciosas e explicitas que negam o exercício do direito à cidade pelas pessoas em situação de rua, que estão impedidas de acesso e usufruto das vantagens, dos bens e serviços e oportunidades disponíveis nas cidades. A partir da realidade em análise, fica claro o desafio de identificar que ações concretas podem ser encadeadas pelo Poder Público no sentido de reverter esse quadro insustável e horrendo. O justo e adequado enfretamento político pelo Estado brasileiro faz-se necessário frente as inúmeras práticas patéticas de violências institucionalizadas ou não que tais pessoas sofrem, combinado com o elevado grau de miserabilidade que vivenciam ou experimentam.

\section{CONSIDERAÇÕES FINAIS}

Infelizmente, o exercício do direito à cidade pelas pessoas em situação de rua ainda corresponde a uma luta pela defesa da construção de um modo de viver imerso em ética, igualdade de oportunidades e liberdade substanciais, para que possa usufruir de tudo àquilo que existe na cidade, e, principalmente, a possibilidade de transformá-la em um espaço radicalmente diverso daquele em que se vive na atualidade, materializado em novos padrões de sociabilidade, permeiem a satisfação dos interesses, e capaz de atender às necessidades humanas frente ao processo deliberado e sistemático que invisibilisa aquelas pessoas.

Estigmatizada pelo Estado e sociedade, a população em situação de rua é alvo da intolerância e do preconceito. As práticas higienizadoras que visam esconder esse fenômeno nos tempos atuais, subtrai-lhes o acesso às políticas sociais e serviços urbanos que são destinados aos brasileiros e às brasileiras, inclusive e principalmente o direito de ir e vir e o direito de permanência nas cidades.

Nesse patamar, o Poder Público é desafiado urgentemente a tratar a população em situação de rua não mais como um caso de polícia, mas sim que, para ela, sejam adotadas políticas públicas estruturantes, intergovernamentais, que dialoguem entre si de forma 
transversal, forjando e sedimentando espaços vitais de uma sociabilidade que se evidencie na lógica do reconhecimento e garantia de direitos. Esse é um dever irrefutável do Estado na perspectiva do alargamento de direitos.

O direito à cidade apresenta uma matriz de cunho humanitário e tem como destinatária toda a coletividade, mas não é isso que se verifica quando se analisa a realidade vivenciada pelas pessoas em situação de rua. Assim, o direito fundamental à cidade sustentável e inclusiva assume dimensão significativa do ponto de vista sociopolítico, vez que revela o compromisso do Poder Público de garantir o respeito e a proteção dos direitos fundamentais para todos os habitantes das cidades, principalmente para as pessoas que se encontram em estado de vulnerabilidade.

Considera-se que a garantia desse direito fundamental à cidade credita ao Poder Público o papel de concretizar as funções sociais da cidade em favor de todos os habitantes, particularmente dos segmentos sociais vulneráveis, compreendida de forma ampla e imbricada à qualidade de vida de todos os seus moradores, aí, incluídas, à toda evidência, as pessoas em situação de rua. É inaceitável que a violência verbal, física e simbólica materializadas de forma explicita ou velada, institucionalizada ou não, continue reafirmando o poder da polícia e a lógica da higienização em face da população em situação de rua.

A cidade deve ser um espaço onde todas as pessoas possam desfrutar e realizar todos os direitos e garantias fundamentais, mediante a oferta de condições de bem estar coletivo com igualdade e justiça social. Desse modo, o direito fundamental à cidade deve conduzir as políticas públicas em direção à construção de uma cidade inclusiva, compartilhada, digna, equitativa, justa, democrática, pacífica, solidária, cidadã, que ofereça condições de vida digna, onde as pessoas consigam satisfazer seus interesses e necessidades básicas e tirar o máximo proveito dos serviços e bens disponíveis. A efetividade desse direito representa um empreendimento ético-jurídico de grande magnitude.

Compreender e garantir o direito à cidade sustentável é contribuir para a promoção da inclusão social. Não existe sustentabilidade onde significativa parcela da população de uma cidade encontra-se marginalizada. A eficácia do direito à cidade sustentável deve ser objeto de permanente otimização, na medida em que tem como objetivo a efetividade de vetores constitucionais, como cidadania e dignidade da pessoa humana (art. $1^{\circ}$, incisos II e III, da Constituição da República) e a construção de uma sociedade justa, livre e solidária, a erradicação da pobreza e da marginalização, a redução das desigualdades sociais, além do combate de todas as formas de discriminação (art. $3^{\circ}$, incisos I, III e IV, da Carta Magna). Todos 
esses vetores representam instrumentos para efetivação do direito à cidade sustentável, o qual depende da atuação estatal para sua concretização.

Como afirmam Valêncio et al (2008, p. 589): A cidade, para as pessoas em situação de rua é, ambiguamente, “[...] o locus de provisionamento mínimo das necessidades, com seus becos e restos, e o locus de sua reiterada rejeição e recriminação, negando-lhe uma vida privada e coletiva dignas". Segmentos sociais dominantes as querem fora da cidade, vendo-as não como pessoas, mas como "coisas desagradáveis", "sujas", "fedorentas" "vagabundas", "criminosas" etc., estigmas esses decorrentes da desumanização das relações sociais, gerando uma visão distorcida do outro, confundindo pessoas com coisas. Isso tem tudo a ver com as pessoas em situação de rua, pois a cidade-mercadoria se vende como um espaço da beleza, da higiene, da exclusividade. Para isso, tais pessoas devem ser afastadas porque "incomodam", inoportunas, apartadas da possibilidade da conquista do direito fundamental à cidade sustentável e inclusiva.

"A cidade mora em mim e eu nela" - dizia Lima Barreto, referindo-se ao Rio de Janeiro do início do século XX. Isso ocorre na atualidade apenas em prol de algumas classes sociais abastadas, não para a população em situação de rua. Para esse público, cabe o entendimento de Chico Buarque, em sua música Assentimento: "A cidade não mora mais em mim”. Estar na cidade e não morar nela é justamente a situação das pessoas que utilizam os logradouros públicos ou não como local de moradia!

\section{REFERÊNCIAS}

ADORNO, Rubens de Camargo Ferreira. Descartáveis urbanos: discutindo a complexidade da população de rua e o desafio para políticas de saúde. Saúde e Sociedade, São Paulo, v. 13, n. 1, p. 56-69, jan.-abr. 2004.

ARENDT, Hannah. Origens do totalitarismo. São Paulo: Companhia das Letras, 1989.

BAUMAN, Zygmunt. Vidas Desperdiçadas. Rio de Janeiro: Zahar, 2005.

BERCLAZ, Márcio Soares; ROLLO, Sandro Cavalcante. A moradia e o direito das pessoas em situação de rua à espera de instituições sensíveis: o que o Ministério Público e Poder Judiciário têm a ver com isso? In: GRINOVER, Ada Pellegrini et al. (Orgs.). Direitos Fundamentais das Pessoas em Situação de Rua. Belo Horizonte: Editora D’Plácido, 2014, p. 675-704.

BRASIL. Decreto no 7.053 de 23 de dezembro de 2009. Institui a Política Nacional para a População em Situação de Rua e seu Comitê Intersetorial de Acompanhamento e Monitoramento, e dá outras providências. 
BRASIL. Lei $\mathbf{n}^{\mathbf{0}} \mathbf{1 0 . 2 5 7}$, de 10 de julho de 2001. Regulamenta os artigos 182 e 183 da Constituição Federal, estabelece diretrizes gerais da política urbana, e dá outras providências.

BRASIL. Lei no 11.977, de 7 de julho de 2009. Dispõe sobre o Programa Minha Casa, Minha Vida - PMCMV e a regularização fundiária de assentamentos localizados em áreas urbanas.

BRASIL. Ministério do Desenvolvimento Social e Combate à Fome. Política Nacional para a Inclusão Social da População em Situação de Rua. Brasília: MDS, 2008.

GOFFMAN, Erving. Estigma: Notas sobre a manipulação da identidade deteriorada. Rio de Janeiro: LTC, 2008.

LEVREBVRE, Henri. O direito à cidade. São Paulo: Centauro, 2013.

MELO, Cíntia de Freitas. População de Rua: entre a exclusão e a justiça social. In: GRINOVER, Ada Pellegrini et al. (Orgs.). Direitos Fundamentais das Pessoas em Situação de Rua. Belo Horizonte: Editora D’Plácido, 2014, p. 51-64.

SILVA, Nilson Tadeu Reis Campos. Alteridade: a identificação da diferença. In: Revista Direitos Culturais. Santo Ângelo, v. 5, n.8, p. 131-166, jan./jun. 2010. Disponível em: http://srvapp2s.urisan.tche.br/seer/index.php/direitosculturais/article/view/361/218. Acesso em: 8 set. 2016.

SILVEIRA, Flavio. Enxergando o invisível: desafios metodológicos de uma (re) construção do olhar. In: CUNHA, Júnia Valéria Quiroga da; RODRIGUES, Monica (Orgs.). Rua: prendendo a contar. Pesquisa Nacional sobre a População em Situação de Rua. Brasília, DF: Ministério do Desenvolvimento Social e Combate à Fome, 2009.

VALÊNCIO, Norma Felicidade Lopes da Silva et al. Pessoas em situação de rua no Brasil: Estigmatização, desfiliação e desterritorialização. RBSE - Revista Brasileira de Sociologia da Emoção, v. 7, n. 21, pp. 556 a 605, dezembro de 2008.

VIEIRA, Antonieta da Costa; BEZERRA, Eneida Maria Ramos; ROSA, Cleisa Moreno Maffei (Orgs.). População em situação de rua: Quem é, Como vive, Como é vista. 3. ed. São Paulo: Hucitec, 2004.

WACQUANT, Loïc. Punir os pobres: a nova gestão da miséria nos Estados Unidos. 2. ed. Rio de Janeiro, Revan, 2003. 